\title{
A computational model of a strongly facilitating synapse
}

\author{
Joanna Jędrzejewska-Szmek ${ }^{1 *}$, Jarosław Żygierewicz ${ }^{1}$, Aleksander Michalski ${ }^{2}$ \\ From Twentieth Annual Computational Neuroscience Meeting: CNS*2011 \\ Stockholm, Sweden. 23-28 July 2011
}

We propose a new model of strongly facilitating synapse. It is described in terms of resources $R$ which can be in two states: available and inactivated (recovery constant $-t_{\gamma}$ ). It assumes that for the release of neurotransmitter to the synaptic cleft a fraction $(u)$ of available resources must bu used (as in [2]). This fraction is elevated by every AP (by a factor $\sim u^{*} \mathrm{U}$ ) and decays in between APs (facilitation constant $-t_{f}$ ). $u$ related to the calcium concentration. It is further assumed that the activation of the neurotransmitter release machinery requires binding of 5 calcium ions to synaptotagmin[3], binding synaptic vesicles to the presynaptic membrane. Hence the postsynaptic current is proportional to $\mathrm{u}^{5^{*}} \mathrm{R}^{*} \delta\left(\mathrm{t}-\mathrm{t}_{\mathrm{AP}}\right)$.
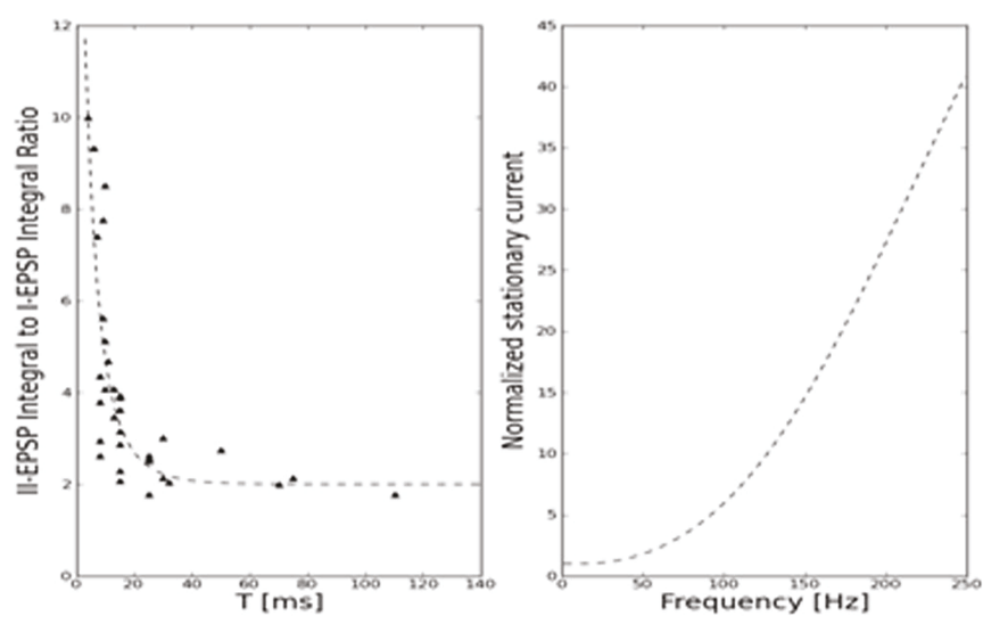

Figure 1 Best fit to the experimental results from [1] and stationary current predictions. Best-fit parameters can be found in Tab. 1.

Table 1 Results of the models fit to the experimental data

\begin{tabular}{llll}
\hline parameter & $t_{f}$ & $U$ & $t_{r}$ \\
\hline Value and 68\% confidence range in & $10 \pm 2 \mathrm{~ms}$ & $0.18 \pm 0.07$ & $130 \mathrm{~ms}$ \\
\hline
\end{tabular}

\footnotetext{
* Correspondence: asia@fuw.edu.pl

'Biomedical Physics, Faculty of Physics, University of Warsaw, ul.Hoża 69, 00681 Warszawa, Poland

Full list of author information is available at the end of the article
}

The model allows to derive analytic formulas for the measures reported in the experimental literature, e.g. EPSP integrals [1] for consecutive action potentials arriving at the synapse. Those measures were used to estimate the model parameters so that it corresponds to the synapses reported in [1]. The obtained parameter values (Table 1 ) are in the physiologically plausible range. The best fit curve is presented in Fig. 1. The model allows to make predictions which can be used to validate it. In our case - the stationary current

\section{() Biomed Central}


(normalized to the typical synaptic current) which can be seen in Fig. 1 - information coding is possible for physiological spike frequencies.

\section{Author details}

'Biomedical Physics, Faculty of Physics, University of Warsaw, ul.Hoża 69, 00681 Warszawa, Poland. ${ }^{2}$ Laboratory of Neurobiology of Development and Evolution, Nencki Institute of Experimental Biology, ul.L.Pasteura 3, 02-093

Warszawa, Poland.

Published: 18 July 2011

\section{References}

1. Thomson AM: Activity-dependent properties of synaptic transmission at two classes of connections made byrat neocortical pyramidal axons in vitro. J Physiol 1997, 502:131-147.

2. Markram $H$, Wang $Y$, Tsodyks M: Differential signaling via the same axon of neocortical pyramidal neurons. Proc Natl Acad Sci U S A 1998, 95(9):5323-532.

3. Fuson KL, Montes M, Robert JJ, Sutton RB: Structure of human synaptotagmin $1 \mathrm{C} 2 \mathrm{AB}$ in the Absence of $\mathrm{Ca} 2+$ reveals a novel domain association. Biochemistry 2007, 46:13041-13048.

doi:10.1186/1471-2202-12-S1-P159

Cite this article as: Jędrzejewska-Szmek et al:: A computational model of a strongly facilitating synapse. BMC Neuroscience 2011 12(Suppl 1):P159.

\section{Submit your next manuscript to BioMed Central} and take full advantage of:

- Convenient online submission

- Thorough peer review

- No space constraints or color figure charges

- Immediate publication on acceptance

- Inclusion in PubMed, CAS, Scopus and Google Scholar

- Research which is freely available for redistribution 